\title{
Application of Box-Behnken Model to Study the Biosorption of Chromium Cr(VI) Ion by Aspergillus niger isolated from Polluted Site
}

\author{
Shobha Shrivastava ${ }^{1}$ and Mayuri Gupta ${ }^{2^{*}}$ \\ ${ }^{1}$ SNGGPG College, Bhopal, Madhya Pradesh, India \\ ${ }^{2}$ Barkatullah University, Bhopal, Madhya Pradesh, India \\ *Corresponding author
}

\section{A B S T R A C T}

Keywords

Response surface methodology

(RSM), Box-

Behnken design

(BBD), Heavy

metal, Biosorption,

Aspergillus niger

Article Info

Accepted:

15 June 2021

Available Online:

10 July 2021
The biosorption of $\mathrm{Cr}(\mathrm{VI})$ metal ion by fungal biomass isolated from polluted soil samples was optimized by using response surface methodology (RSM). The box-behnken design of RSM was used to optimize the parameters such as $\mathrm{pH}$, temperature, initial metal ion concentration and contact time. The isolated strain was identified as Aspergillus niger. Total thirty experiments were used to evaluate the interactions between the selected independent variables. The results showed that the fungal biomass isolated from the polluted site impart an important environmental impact through biosorption of $\mathrm{Cr}(\mathrm{VI})$ metal ions from the metal solution. The maximum removal value of $\mathrm{Cr}(\mathrm{VI})$ obtained was 82.60 percent at $\mathrm{pH} 5.0$ with $103.55 \mathrm{ppm}$ initial metal ion concentration, $35^{\circ} \mathrm{C}$ temperature and contact time of 60 minutes.

\section{Introduction}

The importance of use of various heavy metals in the industrial application has resulted in an increased use (Rao et al., 2014, Saleem et al., 2014) in industries leading to the discarding of heavy metal laden waste material into the environment causing metal pollution (Gautam et al., 2014). The hazardous nature of industrial effluents containing cadmium, chromium, copper, lead, mercury, nickel, palladium, and zinc, makes it compulsory to treat the effluent to control its toxicity (Barakat 2011). Heavy metal pollution poses a serious hazard to both aquatic and terrestrial ecosystems. As a result, scientific community places a high premium on recovering heavy metals from aqueous medium. Metal decontamination, on the other hand, is a difficult operation because all extraction techniques are neither cost-effective nor ecologically benign. To remove heavy metals in industrial effluents, various traditional technologies such as precipitation, reduction, 
coagulation, membrane filtration, ion exchange, and adsorption are already available (Fu and Wang 2011). These traditional methods possess various disadvantages such as high cost and ineffectiveness for lowstrength wastewaters (Farooq et al., 2010) and the sludge is produced (Srivastava and Majumder 2008) during use, many of these methods are less popular than adsorption (Eccles 1999).

Biosorption has evolved as an appealing and viable technology for the removal of metal species from wastewater as a result of rising environmental awareness and the drive for the development of clean remediation strategies for pollution abatement (Gautam et al., 2014). In this process live or dead cells uptake the pollutants through the physico-chemical adsorption or ion exchange. Several biological materials, such as bacteria, algae and fungi, have merged as potential sorbents of heavy metal uptake from wastewater. During mid1970s, the applicability of fungal biomass for adsorption of heavy metals was discovered and has now become an important biosorbent.

Chromium is introduced in the environment via several industrial practices like electroplating, tanning, steel industry, textile and dyeing industry, manufacturing of pigments and refractory materials etc. Chromium exists in environment in two stable forms i.e. $\mathrm{Cr}(\mathrm{III})$ and $\mathrm{Cr}(\mathrm{VI})$ and from these forms $\mathrm{Cr}(\mathrm{VI})$ is highly oxidizing in nature.

Due to its high oxidizing nature, $\mathrm{Cr}$ (VI) is considered as a cancer causing agent. It does not interact directly with DNA, Cr(VI) is reduced to $\mathrm{Cr}$ (III) intra-cellularly via reactive intermediates. Therefore it is necessary the $\mathrm{Cr}(\mathrm{VI})$ ions must be removed before the discharging of effluents. The adsorption technology is the viable method where low cost adsorbents like fungal biomass were used for uptake of $\mathrm{Cr}(\mathrm{VI})$ metal ions.
The biosorption technology is generally used under optimized condition for maximum removal of metal ion from the metal solution. The operating parameters were generally optimized by changing one variable, while keeping other variables constant. But this conventional method is tedious because it requires large number of experiments consuming lot of time. The output generated from these experiments is sometimes unreliable. So a statistical model called response surface methodology (RSM) was introduced to overcome the problems of conventional methods. RSM is basically computational statistical technique which mainly screens out the optimal operational conditions for a particular system.

In view of above, the present study was performed in batch mode for removal of $\mathrm{Cr}(\mathrm{VI})$ from aqueous solution using isolated species of Aspergillus niger. The optimal conditions for the removal of $\mathrm{Cr}(\mathrm{VI})$ were determined by using a Box-Behnken experimental design.

\section{Materials and Methods}

\section{Preparation of biosorbent}

The filamentous fungus tolerant to chromium (VI) was isolated from the selected polluted sites of Bhopal, Madhya Pradesh. The chromium tolerant fungal species isolated was identified as Aspergillus niger by studying its morphological and microscopic characteristics. The A. niger species was allowed to grow on potato dextrose broth at $30 \pm 2{ }^{\circ} \mathrm{C}$ temperature with incubation period of seven days. After incubation period the fungal isolate was collected by filtration through Whatman filter paper. The obtained live biomass was washed several times with deionized water to remove the media components. Further the biomass was deactivated by autoclaving the fungal biomass 
in Erlenmeyer flask at 1.5 atm pressure and $121^{\circ} \mathrm{C}$ temperature for 5 minutes (Schiewer and Volesky, 1995). The obtained biomass was then centrifuged after washing with deionized water. The pellet was collected and dried at $45-50^{\circ} \mathrm{C}$ for 24 hours and then the dried biomass was powdered with mortar and pestle. The collected dried and sieved biomass was further stored in desiccators and used for assessing the biosorption capacity of the fungal biomass (Hajahmadi et al., 2015).

\section{Optimization of parameters with Box- Behnken design}

Biosorption experiments were conducted in batch mode using $\mathrm{Cr}(\mathrm{VI})$ metal ion solution. The stock solution of Cr(VI) metal ion (1000 $\mathrm{mg} / \mathrm{L}$ ) was prepared by dissolving potassium dichromate $\left(\mathrm{K}_{2} \mathrm{Cr}_{2} \mathrm{O}_{7}\right)$ in double distilled water. For obtaining further desired concentrations $(50 \mathrm{mg} / \mathrm{L}$ to $500 \mathrm{mg} / \mathrm{L})$, the stock solution was diluted with double distilled water. The biosorption studies were carried out using $150 \mathrm{ml}$ working metal solution in $250 \mathrm{ml}$ Erlenmeyer flasks. Different parameters viz., $\mathrm{pH}$, temperature, initial metal ion concentration and contact time were adjusted in the metal solution to assess the optimum biosorption conditions. The response surface methodology (RSM) was used to design array of experiments to identify the optimum condition for metal ion biosorption. The biosorbent dosage and agitation speed was kept constant to $1.0 \mathrm{~g} / \mathrm{L}$ and $125 \mathrm{rpm}$ for all the biosorption experiments.

In this study, Box-Behnken design matrix was used to obtain the accurate prediction for operating parameters and to minimize the number of experiments without disturbing the model preciseness. Total thirty experiments were conducted for $\mathrm{Cr}(\mathrm{VI})$ metal ion according to Box-Behnken design. The effect of operating parameters viz., $\mathrm{pH}$, temperature, initial metal ion concentration and contact time were systemically analyzed under biosorption studies.

In box-behnken design, combination of parameters were taken for process variables with varied $\mathrm{pH}$ values ranging from 5 to 9 , temperature ranging from 30 to $40^{\circ} \mathrm{C}, \mathrm{Cr}(\mathrm{VI})$ ion concentration ranging from 50 to 200 $\mathrm{mg} / \mathrm{L}$ and contact time of 30 to 90 minutes. Table 1 depicts different levels and ranges of chosen independent process parameters. The generated data was analyzed by using designexpert statistical software package.

After experimentation, the biosorbent and metal solutions were centrifuged at $7000 \mathrm{rpm}$ for 10 minutes and the collected supernatants were analyzed to determine the residual metal ion concentration. This will provide the uptake of metal ions from solution by the fungal biosorbent.

\section{Result and Discussion}

\section{Optimization of biosorption}

The experiments were statistically analyzed and the effect of process parameters on chromium $(\mathrm{Cr}(\mathrm{VI}))$ removal (\%) was statistically evaluated by using Box-Behnken design. The results obtained from the experiments conducted as per the BoxBehnken design to study the effects of four independent process variables are presented in Table 2.

The adequacy of the model for removal of $\mathrm{Cr}(\mathrm{VI})$ was determined by the sequential model sum of squares, lack of fit tests and model summary statistics. Comparison between various statistical parameters, includes the coefficient of determination (R2), the adjusted R2 and the F-value from ANOVA, was used to identify the best fitting mathematical models of the responses. The 
observed regression coefficient was best for quadratic model showed by the model summary statistics. ANOVA analysis confirmed that the model adequately explained the relationship between the process variables and the response. The ANOVA results are tabulated and shown in table 3 .

The relationship between various process variables and responses were determined where $\mathrm{A}, \mathrm{B}, \mathrm{C}$ and $\mathrm{D}$ denotes $\mathrm{pH}$, initial metal ion concentration, contact time and operating temperature respectively. Values of "Prob > F" less than 0.0500 indicate model terms are significant. The analysis of variance (ANOVA) for $\mathrm{Cr}(\mathrm{VI})$ metal ion removal indicated that the main effects of $\mathrm{pH}$, initial metal ion concentration, contact time, temperature, $\mathrm{pH} \times$ initial metal ion concentration, $\mathrm{pH}^{2}$, initial metal ion concentration $^{2}$ were significant model terms. Values greater than 0.1000 in analysis of variance indicates that the model terms are not significant. Multiple regression analysis of experimental data is resulted in the following equation for biosorption of $\mathrm{Cr}(\mathrm{VI})$ ions.

Biosorption $\mathrm{Cr}=$

$=+39.18-31.57 * A+3.03 * B+1.79 *$

$C+0.90 * D+4.28 * A B+0.97 * D+$

$4.28 * A B+0.97 * A C+0.97 * A D+0.30 *$ $B C-0.54 * B D+0.10 * C D+11.41 * A^{2}+$ $0.77 * B^{2}+1.44 * C^{2}+0.055 * D^{2}$

The "Lack of Fit F-value" of 1.93 implies that it is not significant relative to the pure error. There is a $24.29 \%$ chance that a "Lack of Fit F-value" this large could occur due to noise. Non-significant lack of fit is good. The adjusted R2 is equal to 0.9959 of the quadratic model in equation 1 is in reasonable agreement with the predicted $\mathrm{R} 2$ value i.e. 0.9898. The Model F-value of 508.78 implies the model is significant. There is only a $0.01 \%$ chance that an F-value this large could occur due to noise. From the ANOVA results it was confirmed that the quadratic model was satisfactorily adjusted to the experimental data.

The normal probability plot of studentized residuals are shown in figure 1 . The data points on this plot lie reasonably close to the straight line, supporting the significance of the model which confirms that the assumptions of the analysis were satisfied.

The response surface curves for $\mathrm{Cr}$ (VI) metal ion removal are shown in fig. 2 which analyses the interaction between independent variables.

These three-dimensional mesh diagrams were used to the point where optimum response was pointed along with the effect of each parameter on the process of biosorption (Varsihini et al., 2014).

The six mesh diagrams were obtained by varying $\mathrm{pH}$ and initial metal ion concentration when temperature and contact time were kept constant (Fig. 2a). Similarly the mesh diagram in figure $2 \mathrm{~b}$ was obtained by varying $\mathrm{pH}$ and time while keeping temperature and initial metal ion concentration keeping constant. The 3-d surface (Fig. 2c) was obtained by varying $\mathrm{pH}$ and temperature when contact time and initial metal ion concentration was kept constant.

\section{Optimization of parameters using desirability function}

The desirability functions are very much important for computing optimization of desired goal for each factor and responses.

The possible goals for the present experiment are: with in range $(\mathrm{pH})$, within range (initial metal ion concentration), target (time) and temperature (target) and none (for response). 
Table.1 Process variables in coded and un-coded form for $\mathrm{Cr}(\mathrm{VI})$ ions biosorption using isolated Aspergillus niger strain

\begin{tabular}{|c|c|c|c|c|c|}
\hline Factor & Parameters & Unit & \multicolumn{3}{|c|}{ Range and levels } \\
\cline { 4 - 6 } & & & -1 & 0 & +1 \\
\hline A & $\mathrm{pH}$ & -- & 5.0 & 7.0 & 9.0 \\
\hline B & $\begin{array}{c}\text { Initial Cr(VI) } \\
\text { ion } \\
\end{array}$ & $\mathrm{Mg} / \mathrm{L}$ & 50 & 125 & 200 \\
\hline concentration & & & & \\
\hline C & Contact time & Minutes & 30 & 60 & 90 \\
\hline D & Temperature & ${ }^{\circ} \mathrm{C}$ & 30 & 35 & 40 \\
\hline
\end{tabular}

Table.2 Experimental and predicted response for $\mathrm{Cr}(\mathrm{VI})$ ions using Aspergillus niger

\begin{tabular}{|c|c|c|c|c|c|c|}
\hline \multirow[t]{2}{*}{ Run } & \multirow[t]{2}{*}{ A: pH } & \multirow{2}{*}{$\begin{array}{c}\text { B: Initial metal } \\
\text { ion concentration } \\
(\mathrm{mg} / \mathrm{L})\end{array}$} & \multirow{2}{*}{$\begin{array}{c}\text { C: Time } \\
\text { (Minutes) }\end{array}$} & \multirow{2}{*}{$\begin{array}{c}\text { D: } \\
\text { Temperature } \\
\left({ }^{\circ} \mathrm{C}\right)\end{array}$} & \multicolumn{2}{|c|}{ Biosorption } \\
\hline & & & & & Experimental & Predicted \\
\hline 1 & 9 & 125 & 60 & 30 & 17.32 & 17.20 \\
\hline 2 & 9 & 50 & 60 & 35 & 12.28 & 12.47 \\
\hline 3 & 7 & 50 & 60 & 30 & 35.19 & 35.52 \\
\hline 4 & 7 & 125 & 60 & 35 & 37.23 & 39.18 \\
\hline 5 & 7 & 50 & 90 & 35 & 41.3 & 39.83 \\
\hline 6 & 5 & 50 & 60 & 35 & 83.26 & 84.18 \\
\hline 7 & 7 & 125 & 30 & 30 & 38.56 & 38.09 \\
\hline 8 & 7 & 50 & 60 & 40 & 38.96 & 38.40 \\
\hline 9 & 7 & 125 & 60 & 35 & 38.97 & 39.18 \\
\hline 10 & 5 & 125 & 90 & 35 & 84.95 & 84.42 \\
\hline 11 & 7 & 125 & 60 & 35 & 40.24 & 39.18 \\
\hline 12 & 9 & 125 & 60 & 40 & 19.35 & 20.94 \\
\hline 13 & 9 & 125 & 90 & 35 & 23.56 & 23.21 \\
\hline 14 & 7 & 125 & 30 & 40 & 40.97 & 39.68 \\
\hline 15 & 7 & 125 & 60 & 35 & 39.65 & 39.18 \\
\hline 16 & 7 & 125 & 60 & 35 & 39.09 & 39.18 \\
\hline 17 & 7 & 200 & 90 & 35 & 46.15 & 46.50 \\
\hline 18 & 5 & 125 & 30 & 35 & 83.48 & 82.78 \\
\hline 19 & 5 & 125 & 60 & 40 & 81.09 & 82.14 \\
\hline 20 & 9 & 200 & 60 & 35 & 27.91 & 27.10 \\
\hline 21 & 7 & 125 & 90 & 30 & 40.05 & 41.46 \\
\hline 22 & 7 & 125 & 90 & 40 & 42.87 & 43.46 \\
\hline 23 & 7 & 200 & 30 & 35 & 39.93 & 42.33 \\
\hline 24 & 7 & 200 & 60 & 30 & 43.17 & 42.68 \\
\hline 25 & 7 & 200 & 60 & 40 & 44.77 & 43.39 \\
\hline 26 & 9 & 125 & 30 & 35 & 18.21 & 17.70 \\
\hline 27 & 5 & 200 & 60 & 35 & 81.76 & 81.68 \\
\hline 28 & 5 & 125 & 60 & 30 & 82.95 & 82.29 \\
\hline 29 & 7 & 50 & 30 & 35 & 36.28 & 36.86 \\
\hline 30 & 7 & 125 & 60 & 35 & 39.88 & 39.18 \\
\hline
\end{tabular}


Table.3 Analysis of variance for Cr(VI) metal ion.

\begin{tabular}{|c|c|c|c|c|c|c|}
\hline Source & $\begin{array}{c}\text { Sum of } \\
\text { Squares }\end{array}$ & df & $\begin{array}{c}\text { Mean } \\
\text { Square }\end{array}$ & $\begin{array}{c}\text { F } \\
\text { Value }\end{array}$ & $\begin{array}{c}\text { p-value } \\
\text { Prob }>\text { F }\end{array}$ & \\
\hline Model & 13116.08 & 14 & 936.86 & 508.78 & $<0.0001$ & significant \\
\hline $\begin{array}{c}\text { A-pH } \\
\text { B-Initial metal } \\
\text { ion }\end{array}$ & 11961.24 & 1 & 11961.24 & 6495.74 & $<0.0001$ & \\
$\begin{array}{c}\text { Concentration } \\
\text { C-Time }\end{array}$ & 38.34 & 1 & 38.34 & 20.82 & 0.0004 & \\
\hline D-Temperature & 9.67 & 1 & 9.67 & 5.25 & 0.0368 & \\
\hline AB & 73.36 & 1 & 73.36 & 39.84 & $<0.0001$ & \\
\hline AC & 3.76 & 1 & 3.76 & 2.04 & 0.1733 & \\
\hline AD & 3.78 & 1 & 3.78 & 2.05 & 0.1723 & \\
\hline BC & 0.36 & 1 & 0.36 & 0.20 & 0.6647 & \\
\hline BD & 1.18 & 1 & 1.18 & 0.64 & 0.4364 & \\
\hline CD & 0.042 & 1 & 0.042 & 0.023 & 0.8819 & \\
\hline $\mathbf{A}^{2}$ & 893.24 & 1 & 893.24 & 485.09 & $<0.0001$ & \\
\hline $\mathbf{B}^{2}$ & 4.05 & 1 & 4.05 & 2.20 & 0.1589 & \\
\hline $\mathbf{C}^{2}$ & 14.16 & 1 & 14.16 & 7.69 & 0.0142 & \\
\hline $\mathbf{D}^{2}$ & 0.020 & 1 & 0.020 & 0.011 & 0.9175 & \\
\hline Residual & 27.62 & 15 & 1.84 & & & \\
\hline Lack of Fit & 21.93 & 10 & 2.19 & 1.93 & 0.2429 & not \\
\hline Pure Error & 5.69 & 5 & 1.14 & & & \\
\hline Cor Total & 13143.70 & 29 & & & & \\
\hline & & & & & & \\
\hline & & & & & \\
\hline
\end{tabular}

Fig.1 Normal Probability plot of studentized residuals versus normal \% probability for the $\%$ removal of $\mathrm{Cr}$ (VI) metal ions.

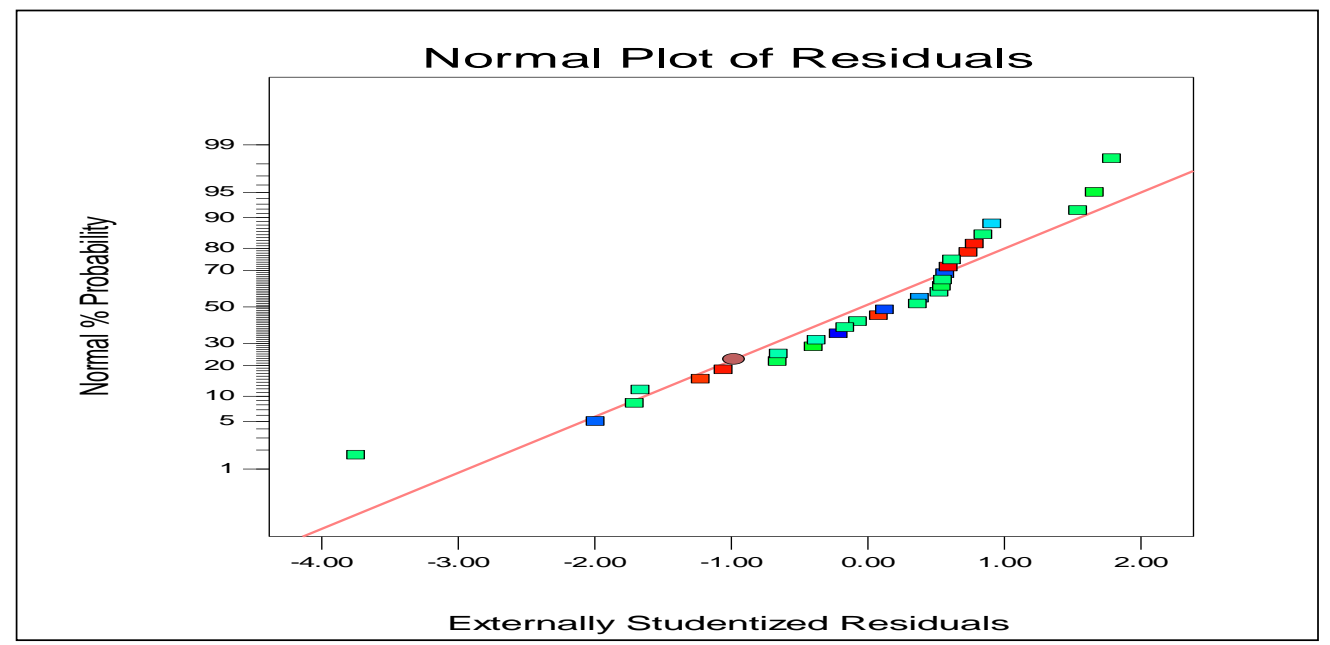


Fig.2 Three dimentional response surface plots showing the effect of different independent process variables on $\mathrm{Cr}(\mathrm{VI})$ biosorption using $\mathrm{A}$. niger

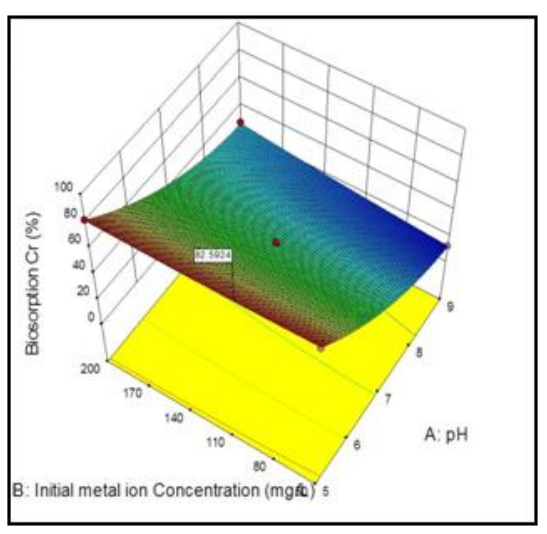

(a)

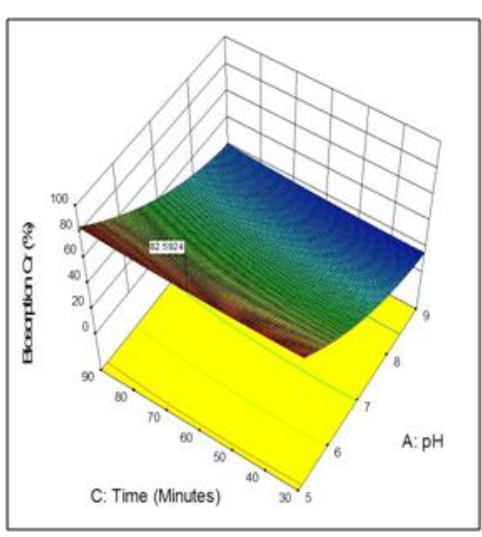

(b

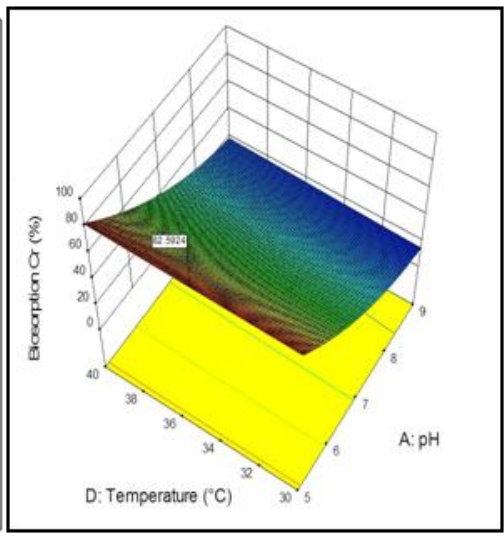

(c
The overall desirability function was determined finally by combining all the desired goals. The optimization of $\mathrm{Cr}(\mathrm{VI})$ metal ion biosorption was determined at an initial concentration of $103.55 \mathrm{mg} / \mathrm{L}, \mathrm{pH} 5.0$, temperature $35^{\circ} \mathrm{C}$ and contact time of 60 minutes.

Under these optimized conditions, maximum removal of $\mathrm{Cr}(\mathrm{VI})$ metal ion of 82.60 percent was recorded with desirability function of 0.99 . This value of desirability shows that the estimated function may represent the experimental model and desired conditions. The results obtained in this study are comparable to the study of Mondal et al., 2017.

The strain of Aspergillus niger isolated from polluted sites was further selected for biosorption studies. In this study process parameters for efficient removal of $\mathrm{Cr}(\mathrm{VI})$ metal ions were optimized using BoxBehnken design of RSM. The quadratic model suited best and validated the good agreement between the experimental values and the predicted values. The high coefficient of determination $\left(\mathrm{R}^{2}\right)$ was shown by the Analysis of variance (ANOVA) studies. The optimum conditions were selected which showed the maximum efficiency for removal of metal ions from metal solution with the help of numerical optimization.

\section{References}

Barakat, M. A. (2011). "New trends in removing heavy metals from industrial wastewater." Arab. J. Chem., 4(4), 361-377.

Eccles, H. (1999). "Treatment of metalcontaminated wastes: Why select a biological process?" Trends Biotechnol., 17(12), 462-465.

$\mathrm{Fu}, \mathrm{F}$., and Wang, Q. (2011). "Removal of heavy metal ions from wastewaters: A review." J. Environ. Manage., 92(3), 407-418.

Gautam, R. K., Mudhoo, A., Lofrano, G., and Chattopadhyaya, M. C. (2014). "Biomass-derived biosorbents for metal ions sequestration: Adsorbent modification and activation methods and adsorbent regeneration." J. Environ. Chem. Eng., 2(1), 239-259.

Hajahmadi, Z., Younesi, H., Bahramifar, N., 
Khakpour, H., \& Pirzadeh, K. (2015). Multi-component isotherm for biosorption of $\mathrm{Zn}$ (II), $\mathrm{CO}$ (II) and $\mathrm{Cd}$ (II) from ternary mixture onto pretreated dried Aspergillus niger biomass. Water Resources and Industry, 11, 71-80.

Mondal, N. K., Samanta A., Dutta Shampa, Chattoraj S., (2017). Optimization of $\mathrm{Cr}(\mathrm{VI})$ biosorption onto Aspergillus niger using 3-level Box-Behnken design: Equillibrium, kinetic, thermodynamic and regeneration studies. Journal of Genetic Engineering and Biotechnology., http://dx.doi.org/10.1016/j.jgeb.2017.0 1.006 .

Rao, G. K., Kumar, A., Bhunia, M., Singh, M. P., and Singh, A. K. (2014). "Complex of 2-(methylthio) aniline with palladium(II) as an efficient catalyst for Suzuki-Miyaura C-C coupling in ecofriendly water." J. Hazard. Mater., 269, 18-23.

Saleem, F., Rao, G. K., Kumar, A., Kumar, S., Singh, M. P., and Singh, A. K. (2014).
"Palladium(II) complexes bearing the 1, 2, 3-triazole based organosulfur/selenium ligand: Synthesis, structure and applications in Heck and SuzukiMiyaura coupling as a catalyst via palladium nanoparticles." RSC Adv., 4(99), 56102-56111.

Schiewer, S., \& Volesky, B. (1995). Modeling of the proton-metal ion exchange in biosorption. Environmental science \& technology, 29(12), 3049-3058.

Srivastava, N., and Majumder, C. (2008). "Novel biofiltration methods for the treatment of heavy metals from industrial wastewater." J. Hazard. Mater., 151(1), 1-8.

Varshini C. J. S., Das D., Das N., (2014). Optimization of parameters for cerium(III) biosorption onto biowaste materials of animal and plant origin using 5-level Box-Behnken design: Equilibrium, kinetic, thermodynamic and regeneration studies. Journal of Rare Earths. Volume 32, Issue 8, Pages 745-758.

\section{How to cite this article:}

Shobha Shrivastava and Mayuri Gupta. 2021. Application of Box-Behnken Model to Study the Biosorption of Chromium $\mathrm{Cr}(\mathrm{VI})$ Ion by Aspergillus niger Isolated from Polluted Site. Int.J.Curr.Microbiol.App.Sci. 10(07): 414-421. doi: https://doi.org/10.20546/ijcmas.2021.1007.045 